\title{
The Use of 3D-Printing Technology in Calculus Education: Concept Formation Processes of the Concept of Derivative with Printed Graphs of Functions
}

\author{
Frederik Dilling ${ }^{1} \cdot$ Ingo Witzke $^{1}$
}

Published online: 16 April 2020

(C) The Author(s) 2020

\begin{abstract}
3D-printing technology has become increasingly important in recent years, offering many possibilities for mathematics teaching and learning. From our point of view, the field of calculus seems to be particularly suitable for the use of 3D-printing. Using the example of 3D-printed graphs of functions, the use of this technology in calculus is discussed within the three approaches of Grundvorstellungen, Subjective Domains of Experience and Empirical Theories. An empirical study, based on the qualitative content analysis according to Philipp Mayring, examines the influence of the models on concept formation processes in the context of derivatives. The focus is on the following research question: "What are the characteristics of concept formation processes of the concept of derivative in the context of 3D-printed graphs of functions?"
\end{abstract}

Keywords 3D-printing $\cdot$ Derivative $\cdot$ Calculus $\cdot$ Grundvorstellung $\cdot$ Subjective domains of experience $\cdot$ Printed graphs of functions

\section{D-Printing in Mathematics Education}

3D-printing technology is a relatively new tool with potential for mathematics education. It can be described as an additive manufacturing method allowing for digital models constructed with CAD-software to be transformed layer by layer into a real model made out of liquid plastic (see Gibson et al. 2014). Witzke and Hoffart (2018) detail three options for using the 3D-printing technology in the classroom. First, there is the possibility to reproduce

Frederik Dilling

dilling@mathematik.uni-siegen.de

Ingo Witzke

witzke@mathematik.uni-siegen.de

1 Mathematics Education, University of Siegen, Herrengarten 3, 57072 Siegen, Germany 
existing manipulatives. Another option is the development of manipulatives by the teacher (and also in co-operation with students). This enables their adaption according to the individual requirements of the students. If the students are also involved in the printing process and detect the structure of the printed object, the development of black boxes can be avoided. Finally, the students can also develop 3D-printed objects on their own. In relation to inquiry-based learning, this third option is the most interesting application for education.

In mathematics education, several articles on this last option have been published. Most of them examine the relationship between the use of 3D-printing and the learning of geometry. Panorkou and Pratt (2016) investigate the potential of CAD-software for developing ideas about dimensions. The results show that even young students can develop adequate ideas of directions, positions, orientations and containment of parameters in dealing with the software. $\mathrm{Ng}$ (2017) explains the benefits of 3D-printing technology for learning about the volume of solids. For this study, qualitative data was collected in a class project which included the design of solids with CAD-software, the printing of these solids and the calculation of their volumes by hand on paper. It turned out that the students developed a deep understanding of the relationship between changes of the linear dimensions of the objects and their volumes through the open approach of the design process with multiple revisions of the objects.

This article discusses the use of 3D-printing technology in the field of calculus and focuses on the creation of visualizing models in the classroom. The use of such models for the teaching of mathematics and the construction of adequate notions of mathematical objects goes back a long way and is particularly apparent in the work of the nineteenthcentury German mathematician Felix Klein. In his mathematics classes, he used concrete, haptic examples of mathematical objects that were examined by the students. Learning with such objects, according to Klein, was particularly beneficial when they were developed by the students themselves:

As today, the purpose of the model was not to compensate for the weakness of the view, but to develop a vivid clear perception. This aim was best achieved by those who created models themselves. (Klein 1927/1978, p. 78)

Thus, the creation of mathematical visualizing models can be a promising part of the processes of learning mathematics, especially in the phases of concept formation. 3Dprinting technology makes it possible to create appropriate models in the classroom with little effort. By constructing the objects on the computer, students can apply previously acquired knowledge and work with a high level of accuracy. In this way, the ideas of Felix Klein can meaningfully enrich modern mathematics teaching (see Halverscheid and Labs 2019).

Dilling (2019) presents different visualizing models created with the 3D-printing technology in the field of calculus. Three of the applications will be described shortly, among them the three-dimensional representations of graphs of functions examined in the empirical study on which this article is based. One of the 3D-printing applications that can be used in the integral calculus are solids of revolution (see Fig. 1, left), which can be easily constructed with CAD-software. For this purpose, the surface under the graph of a function needs to be constructed in a two-dimensional sketch and to be extruded in rotation. In this way, the body of revolution is created directly. Thus, the design process shows the connection between the surface that is rotated and the resulting body of revolution. The volumes of the models can 

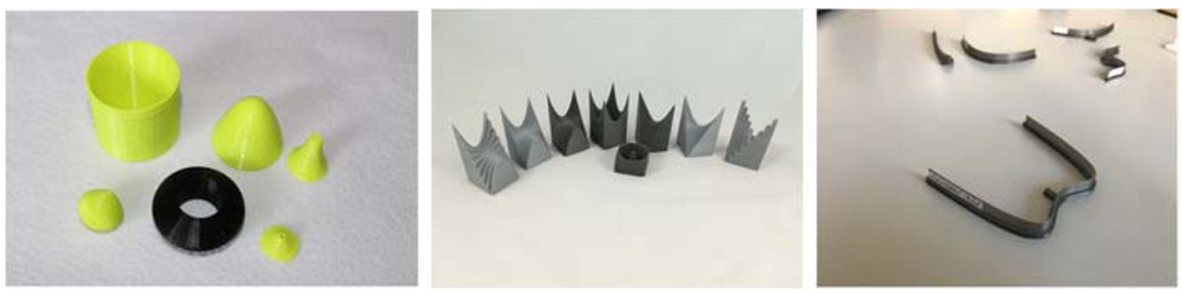

Fig. 1 3D-printed models of solids of revolution (left); graphs of functions of two variables (middle); graphs of functions of one variable (right) (Dilling 2019)

be measured by the change of the liquid level during immersion in a liquid container and compared with the calculated value.

Functions of two variables provide another application of the 3D-printing technology in the context of calculus (see Fig. 1, centre). The OpenSCAD-based software Graph Printer $(2 \mathrm{~V})$ allows students to generate three-dimensional representations of graphs simply by entering the equation of the function and the intervals for the two variables. The models can be used in calculus education for the topic 'arrays of functions'. More traditional approaches usually use two-dimensional graphical representations generated using dynamic geometry software. This is connected to the challenge that the function is only representable by one parameter at a time. By using the three-dimensional printed model, the change in the graph when varying the parameter becomes visible and can even be sensed qualitatively by touching the object.

One last application of 3D-printing technology in calculus is the three-dimensional model of a graph of a real function of one variable (see Fig. 1, right; Fig. 3). This application is examined later in this article in relation to an empirical study. Similar to the above-described software, Graph Printer enables the individual creation of models of functions of one variable by entering the equation of the function and the interval. The generated model is a graph of a real function raised $1 \mathrm{~cm}$ off the plane. In this way, the model enables students to sense properties of the graph and develop concepts of differential calculus in an action-oriented way.

Visualizing models can also be created by 3D-pens, which are not 3D-printers but share some of the same affordances we have described above. They enable the free-hand creation of three-dimensional objects by extruding heated plastic. Students can trace graphs of functions and a movable tangent line with the 3D-pens (see $\mathrm{Ng}$ et al. 2018). $\mathrm{Ng}$ and Sinclair (2018) have investigated how such exploration scan affect the learning of calculus. The 3D drawings of the functions enabled the development of the concept of function on a physical level, while the third dimension allowed a tangent line to be moved along the graph, providing occasions for gestural forms of reasoning. The 3D-drawings were more than prefabricated physical manipulatives, since they were successively created by the drawing itself. In this way, the process character of functions was emphasized.

\section{A Theoretical Framework: Grundvorstellungen, Subjective Domains of Experience and Empirical Theories}

In this article, the influence of 3D-printed models of graphs of functions on conceptualization processes of the concept of derivative will be investigated. For this purpose, 
the concept of Grundvorstellungen is used as a normative perspective on the teaching of the concept of derivative. The conceptions developed by the students are reconstructed with the help of the concept of subjective domains of experience in a descriptive way. Finally, the concept of empirical theories provides a structuring and explaining framework for the whole investigation.

\section{Grundvorstellungen: A Normative Perspective}

The approach of the so-called subject-matter didactics (Stoffdidaktik, in German) originated in German-speaking countries and focuses on the mathematical content to be taught. The main objective is to facilitate the access and the understanding of mathematics on the basis of an analysis of the mathematical content (see Hußmann et al. 2016). The concept of Grundvorstellungen (= basic ideas), according to vom Hofe (1995a), was developed within this approach, in order to facilitate the teaching of concepts. In general, these are used normatively and describe relevant aspects and ideas for students based on the evaluation of mathematical content by expert educators (researchers and teachers). vom Hofe (1995a) described the Grundvorstellungen concept as follows (cited according to vom Hofe and Blum 2016):

This concept describes the relationships between mathematical content and the phenomenon of individual concept formation. The numerous treatments that the GV concept has received over time nonetheless focuses on three particular aspects of this phenomenon, albeit with different emphases among these treatments:

The constitution of meaning of a mathematical concept by linking it back to familiar knowledge or experiences, or back to (mentally) represented actions,

The generation of a corresponding mental representation of that concept; that is, an 'internalization', which (following Piaget) enables operative action at the level of thought,

The ability to apply a concept to real-life situations by recognizing a corresponding structure in subject-related contexts or by modelling a subject-related problem with the aid of mathematical structures. (p. 230)

This construct, which is popular in German-speaking countries, can be related to the internationally well-known 'concept image' and 'concept definition' (Tall and Vinner 1981). Simplified, the 'concept definition' is "a form of words used to specify [the] concept" (p. 152) and emphasizes the technical description, while the 'concept image' describes "the total cognitive structure that is associated with the concept, which includes all the mental pictures and associated properties and processes" (p.152). Grundvorstellungen can be seen as a kind of mediator between the 'concept definition' and the individual conceptions of students, as normative categories (formulated with respect to empirical observation of students) that may guide teachers in the development of specific learning contexts. 
The concept of functions is decisive for the formation of concepts in calculus. According to Vollrath (1989), there are three aspects of functional thinking, also called the Grundvorstellungen of the concept of function:

- assignment: Exactly one $\mathrm{f}(x)$ is assigned to each $x$;

- covariation: The change of $\mathrm{f}(x)$ when changing $x$;

- object: The functional correlation considered as a whole.

These Grundvorstellungen are consistent with the findings of other researchers in the field of functions (e.g. Dubinsky and Harel 1992, for object; Thompson and Carlson 2017, for covariation; Vinner and Dreyfus 1989, for assignment). Carlson (1998) emphasizes the importance of covariational reasoning for representations of dynamical events involving continuously changing phenomena that are part of most applied problems in beginning calculus. The Grundvorstellung of covariation is in direct relation to the rate of change. As empirical studies have shown, many students struggle with regard to this specific Grundvorstellung (see Malle 2000). In order to prepare students for the differential calculus of high school adequately, covariation should be emphasized. How 3D-printing technology supports the Grundvorstellung of covariation will be discussed in detail later.

Various authors have applied the concept of Grundvorstellungen also to other concepts in the field of calculus (e.g. Greefrath et al. 2016). For the study described in this article, the Grundvorstellung of the derivative as the tangent slope is of particular importance. Students already come into contact with the slope of straight lines in middle school. The concept of the tangent is also already known to students from the geometric context of the circle. An extension of these concepts is necessary for the purposes of calculus. For example, the tangent is no longer defined as the straight line that touches the graph at exactly one point, but it is the straight line that adapts locally optimally to the course of the graph. The Grundvorstellung of the derivative as the tangent slope includes these ideas and interprets the derivative of a function at a point as the slope of the tangent at this point. Similar considerations, albeit that do not explicitly refer to the concept of Grundvorstellungen, can be found in Hirst (1972) and Tall (1985).

\section{Subjective Domains of Experience: A Descriptive Perspective}

The concept of 'subjective domain of experience' (SDE) (see Bauersfeld 1983) can be used to describe the developed conceptions of the students when working with the 3Dprinted manipulatives in the empirical study. According to this theoretical framework, human experiences are always linked to a specific context and knowledge should therefore be described as separated according to their situational link. Individual experiences are stored in the memory in separate SDEs. Additionally, an SDE includes the cognitive dimension of an experience as well as motoric skills, emotions and valuations. The 'society of mind' forms the totality of the SDEs of an individual. SDEs are organized non-hierarchical, cumulative and compete for activation within this system. The repetition of a similar situation leads to a consolidation and, thus, to a more effective activation of an SDE. 
Language has an important role in linking existing SDEs. As a term acquires meaning, especially in connection with other terms, each SDE has its own specific language (see Tiedemann 2016). A generalization of terms occurs through the active attempt to recognize structural equalities in two different SDEs, e.g. by the establishment of an analogy, and in this way forms a new SDE that enables a networking of the original SDE (Bauersfeld 1983). For the development of mathematical concepts with the use of manipulatives, this means creating a connection between the mathematical structure and the structure of the manipulative that is stored in different SDEs. This comparison can be conducted only from the perspective of the new SDE, whose formation requires an active construction of meaning by the learner, in which he/she ascribes a certain meaning to the manipulative. Otherwise, an alternative construction within an already existing SDE emerges, which can result in misconceptions.

The concept of SDE is, in important aspects, comparable to the concept of situated learning according to Lave and Wenger (1991). They describe in detail the dependence of learning on the particular learning context as well. But, in contrast to the concept of situated learning, the concept of SDE places the spotlight on the description of experience-based learning within initially isolated SDEs as mental unities, as well as the generation of connections between the SDEs.

The concepts of Grundvorstellungen (vom Hofe 1995a) and SDE (Bauersfeld 1983) can be combined in a common concept for teaching and learning of mathematics. Grundvorstellungen offer the possibility to develop important aspects of a mathematical content based on its analysis and to specify them more precisely for teaching. Thus, they are used as a normative perspective - as the teacher's guiding categories for the development of specific learning contexts. The present case deals with the Grundvorstellungen of function according to Vollrath (1989) and of derivative. Students develop SDEs when interacting in learning contexts. Thus, SDEs can be used to reconstruct and describe the conceptions developed by the students. They provide a descriptive perspective that is related to the normative concept of Grundvorstellungen (see vom Hofe 1995b).

\section{Empirical Theories}

The concept of empirical theories, according to Burscheid and Struve (2010), is used to describe the development of students' knowledge in an empirical-orientated mathematics class. Accordingly, the mathematical knowledge of children is of an empiricalphysical nature. It refers to specific domains of their experience and is therefore linked to a context. These subjective domains of experience are developed by dealing with real phenomena, so that an ontological connection of mathematical knowledge is created with reference to certain empirical-physical objects.

The structure of students' SDEs has a major influence on the development of concepts and argumentation in the classroom. Therefore, an adequate reconstruction of the knowledge structure of students requires a description of their SDEs, as well as the corresponding reference objects and relations. According to the approach of 'theory theory' (Gopnik and Meltzoff 1997), children develop knowledge about certain phenomena of reality in a similar way to scientists in the experimental natural sciences. The knowledge of learners can then be described with the help of empirical theories about these phenomena. 
Empirical objects and methods are important in calculus classes at school. For instance, Tall (2003) makes a distinction between three worlds of calculus. The world of embodiment is represented by perceptions of change and growth; the world of symbolism by problem solving with the algorithms of differentiation and integration; the world of formalism by using an axiomatic structure. Calculus education at school is mostly limited to the first two worlds. Witzke (2014) obtains similar results from a textbook analysis. At university, calculus is often described as a prototype of formal mathematics, whereas calculus teaching at school often involves an empirical belief system shaped by material and illustrations (empirisch-gegenständliche Auffassung von Mathematik). If calculus is consequently taught with the support of visual representations and illustrative material, students develop empirical theories about these representations. For this reason, this article focuses on the empirical belief system of the students within the framework of empirical theories according to Burscheid and Struve (2010).

The concept of empirical theories in the context of school mathematics has much in common with the 'laboratory mathematics approach' of Arzarello et al. (2012), who describe the development of mathematical knowledge with (digital) tools in an experimentally oriented environment. In contrast, the concept of empirical theories does not focus specifically on tools, but rather on empirical objects in general. The concept of empirical theories is used in order to describe the interaction with digital as well as physical objects.

\section{The Software Graph Printer and 3D-Printed Graphs of Functions}

The application of the 3D-printing technology investigated in this article is the software Graph Printer ${ }^{1}$ (Dilling 2019). It enables the user to generate three-dimensional representations of graphs of functions simply by entering the function term and the interval. Various other settings can be adjusted, such as the addition of indicated coordinate axes or the entire co-ordinate system. In addition, two graphs can be displayed simultaneously. The software is programmed with the script-based, CAD-software OpenSCAD. A screenshot of the user interface is shown in Fig. 2.

The 3D-printing technology enables the user to produce a physical object from a virtual one. Such objects can be seen in Fig. 3.

In general, one distinguishes at least four forms of representation of a function: the function term or equation, the table, the graph and a verbal description of a correlation. The software Graph Printer connects the two forms 'function term' and 'graph', similar to a function plotter. When entering the term of a function, a graph is automatically generated. The 3D-printed model is a physical object that can be touched and experienced qualitatively. In this way, graphs of functions can also be made accessible to visually impaired people (see Hofmann et al. 2018). The printed objects are similar to the representation as a graph, but there are also many differences. A connection to the iconic representation can be established by ink-stamping the graph on a sheet of paper.

The 3D-printed models are especially suited for supporting the Grundvorstellung of covariation. It is possible to experience the correlating change of the function values by

\footnotetext{
${ }^{1}$ The software can be downloaded from the website of the University of Siegen (https://www.uni-siegen. de/fb6/didaktik/personen/frederik-dilling/materialien.html?lang=de).
} 


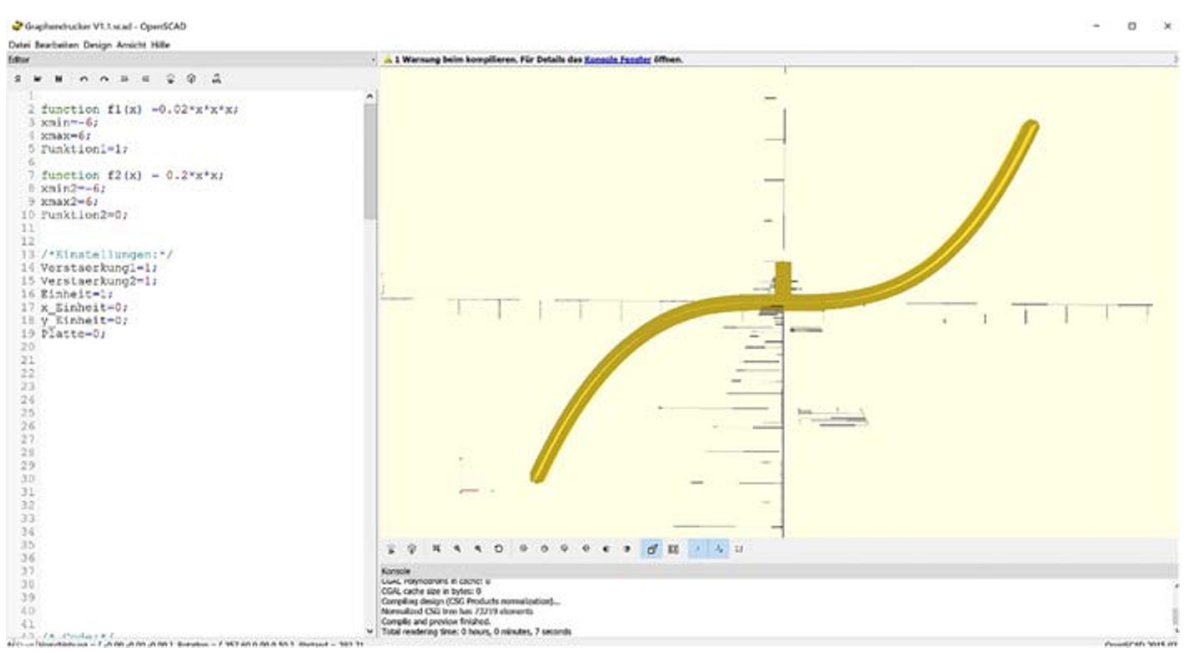

Fig. 2 Screenshot of the user interface of the software Graph Printer

sliding along the graph with one finger. The actual touching of the physical objects can lead to "new gestural forms of thinking" (Ng and Sinclair 2018, p.309), as shown in their study. The idea of covariation is directly connected to the rate of change and therefore of high importance in the calculus preparation.

In a study on beliefs of school-calculus, Witzke and Spies (2016) were able to show that concepts such as continuity or differentiability are rarely used and understood by students. The development of such concepts can be supported by the 'embodied approach to the calculus' described by Tall (2013). When tracing the model with the fingertip, students can "feel the continuity of the graph as dynamic continuity" (p. 300). The changing slope can be perceived by sliding across the model with the extended hand. Local linearity can be seen by covering parts of the graph. With such actions, a conceptual foundation for a later formalism can be built. The actions are visualized in Fig. 4. They can actually be performed on the 3D-printed models, so that the concepts continuity and differentiability are first developed qualitatively. This approach fosters in particular the Grundvorstellung of the derivative as a tangent slope.

\section{An Empirical Study on Concept Formation Processes with 3D-Printed Graphs}

This section reports on an empirical study conducted at the University of Siegen in November, 2017. The data material has already been analyzed in the context of designbased research in Dilling (2019) and Dilling and Witzke (2018). In this article, we focus on the concept formation processes of the concept of derivative of the students. At school, concepts are usually developed by using empirical contexts, especially drawings and application frameworks. Until now, 3D-printed models have rarely been used in calculus. The study focused on the research question: What are the characteristics of concept formation processes of the concept of derivative in the context of 3D-printed graphs of functions? 


$$
\square
$$


This question can be subdivided into several sub-questions, with reference to the presented theoretical framework:

- Which SDEs of the students can be reconstructed?

- Is there a connection between the initially isolated SDEs?

- Which elements of SDEs concern the relevant Grundvorstellungen of the concepts of function and derivative?

- Which objects of reference are central to the concept formation processes of the students?

In order to generate initial results to answer these questions, a qualitative setting was chosen. The methodology and conditions are described in detail in the following subsection.

\section{Methodology and Conditions}

In order to examine the concept formation processes supported by 3D-printing technology, five students were videotaped in a qualitative case study setting while working with the software Graph Printer and the 3D-printed graph models. The students were in the 10th grade of a German high school and were introduced to differential calculus before the start of the study. The group was put together heterogeneously based on the students' performance in mathematics (Dilling 2019). Tasks and questions were given to the students in text form and they were asked to respond in writing. The students were deliberately given only one copy per group (groups of two or three), so that the answers could be worked out through a negotiation process. In order not to restrict the students' willingness to talk and to minimize questions to the interviewing person, the students were alone in the room most of the time.

In order to enable the students to familiarize themselves independently with the models, a total of four questionnaires or task sheets were issued consecutively. First, the students were provided with a task sheet for working with the Graph Printer software. In the first task, the students were asked to create an arbitrary function with the software. Afterwards, they were asked to describe their understanding of a function, the representation on the computer screen and the differences to the graphs created with a graphing calculator. In the second task, the students were asked to construct using the software the parabola with the function equation $f(x)=0.2 x^{2}$.

Subsequently, the students were able to start printing the constructed objects. Furthermore, they were provided with an additional task sheet with questions about the constructed parabola model, as well as a pre-printed version of that model (see Fig. 3 ). The students were first asked to describe the model and to explain possible activities that could be done with it. Then they were asked to explain issues from the calculus lessons that could be discussed about the models, as well as similarities and differences between the model and the representation on the computer screen.

The images of the two mental actions on the concepts of continuity and differentiability proposed by Tall (2013), which were already explained in the previous section (see Fig. 4), were presented to the students on a third task sheet. They were asked to perform the actions on the models and then describe what they noticed and which 
issues from the calculus class related to the action they could remember. In addition, possible differences between the two actions were explicitly requested.

The last task sheet contained questions about the qualitative course of another graph, which was handed out to the students as a printed model for this purpose (see Fig. 3). This was the graph of the function $f(x)=0.03 x^{4}-0.3 x^{2}$, but the equation of the function was not communicated to the students, in order not to influence the qualitative processes. The students were asked in which areas the graph of the function rises, what happens at the points of change, whether something special is visible at these points and how the slope between these points changes. The students were also asked to explain possible symmetries of the graph by using the models. In total, the survey took about three hours for each group.

For the analysis, the videotaped material was transcribed according to the rules of Dresing and Pehl (2015). The generated data was categorized using the method of qualitative content analysis according to Mayring (2000, 2010). The summarizing content analysis was performed in four steps. First, the data to be analyzed was described in detail. In the present case, the analyzed data included the complete transcripts of the two interviews. The unit of analysis, the smallest analyzed part of the text, was each meaningful statement of the students.

In the second step, the relevant parts of the text were summarized in a form limited to content description (paraphrasing). For example, the part of the text, "Student C: [Holding the model in his hand] This is some kind of plastic, isn't it? You can really see that this is all still a layer over there" was paraphrased to "Student C identifies the material of which the model is built as plastic". The paraphrases are generalized at a defined level of abstraction, e.g. "The students emphasize outward characteristics of the 3D-models". The number of generalized statements was then reduced several times by increasing the level of abstraction and removing statements with the same meaning. In the third step, the statements were compiled in a system of categories that was then checked based on the material in the fourth step. The system of categories is described in detail in the following sections. An illustration of the process of summarizing content analysis is shown in Fig. 5.
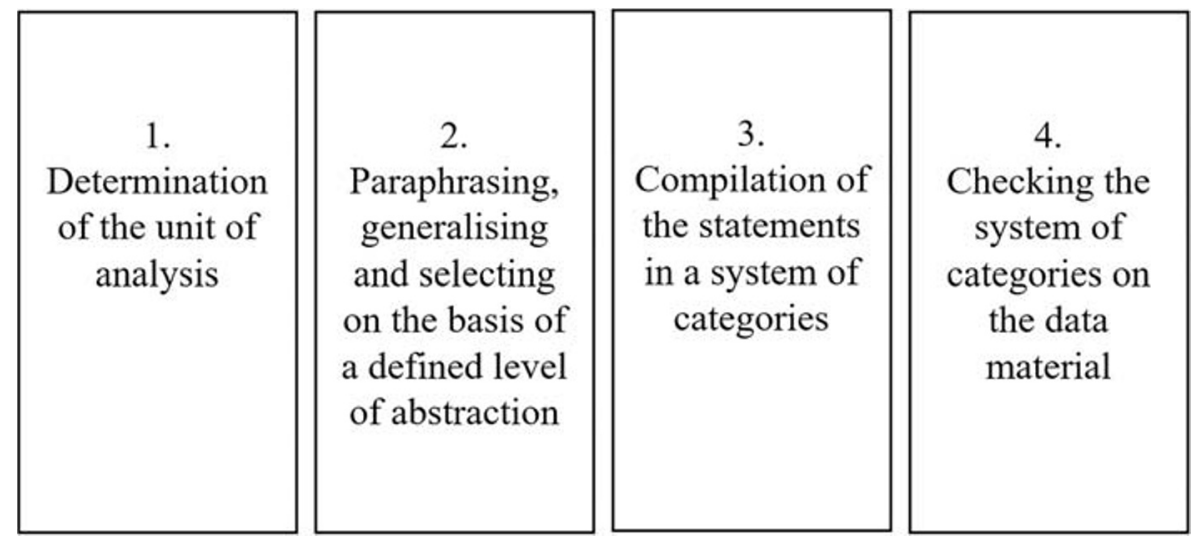

Fig. 5 Simplified illustration of the qualitative content analysis in relation to Mayring (2010, p.70) 


\section{Results and Interpretation}

The analysis of the transcribed learning situations according to the qualitative content analysis with regard to the research questions produced a total of nine inductively formed categories. In order to improve the structuring of the statements, they were assigned to three main categories, which are explained in more detail in Table 1 and are related to the underlying research questions.

In the following section, the different categories are described in more detail by interpreting parts of the data material associated to the categories. For this purpose, the appropriate parts of the transcripts were translated into English.

\section{Category 1: Subjective Domains of Experience}

Three categories of SDEs could be reconstructed from the statements and descriptions of the students. The SDEs reflect the different working phases of the structure of the study (software Graph Printer and 3D-printed models), as well as the previous experiences of the students. These are the contexts and they differ in particular by the different objects of reference in the arguments of the students, as well as a specific use of language in the different situations.

C1.1 Previous Experiences Some of the students' statements refer to experience and knowledge they have previously had and made in mathematics lessons. One of those statements can be found in the following exchange, where two students think of the definition of a function used in their mathematics class:

Student D: Now we have to [Reading the assignment] "What is a function?"

Student E: Hmm. [Laughing]

Student D: What a function is. Yes, a function is .... We really did this with $\mathrm{Mr}$ $\mathrm{X}$.

Student E: Um, an equation.

Student D: Yes, an equation that describes the shape of a parabola.

In this situation, the students consider the question of what a function is. For this, they rely on their previous experiences from the mathematics lessons. In the opinion of the students, a function is an equation (they probably refer to the equation of a function) that determines the shape of a parabola (they probably refer to the graph of a function). Thus, the object of reference to the concept of

Table 1 Inductively formed system of superordinate categories

\begin{tabular}{ll}
\hline Category & Definition \\
\hline C1: Subjective domains of experience & All parts that indicate the development and connection of SDEs. \\
C2: Concept formation derivative & $\begin{array}{l}\text { All parts that indicate the formation of the concept of derivative. } \\
\text { All parts that indicate empirical objects of reference in the } \\
\text { conceptualizations of the students. }\end{array}$
\end{tabular}


function is the graph, the equation serves to describe or construct the graph. This shows the importance of previous experience in the students' conceptual development processes. These experiences form different SDEs, which were already developed before the study and which influence the concept formation in the study. They are summarized in the category 'Previous Experiences'.

C1.2 SDE 'Software Graph Printer' Many statements of the students concerned the work with the software Graph Printer. A short excerpt of a student dialogue is shown below:

Student B: Actually, you could do a really cool function, not such a boring parabola.

Student C: Let's try it out, it'll look like this. [Drawing with the finger in the air] It's to the power of three. We can experiment freely and try different functions.

In this part, the students explain that the software can be used to experiment with functions - the students use the program freely and creatively. It could be observed in other situations that the students tested the appearance of different functions and the effect of functional parameters on the model within the software. The setting options of the software were also tested extensively. The results suggest that the program was suitable for explorative work with functions and that students were highly interested in such work. In this way, the process of concept formation can take place in a student-centred and constructive manner. The experiences on the computer seem to stimulate experiences that are stored in a SDE termed 'Software Graph Printer'.

C1.3 SDE '3D-Printed Models' Many statements of the students also referred to the 3Dprinted models of graphs of functions. A short excerpt can be seen below, showing students' handling of such a model:

Student B: You can feel the parabola.

Student C: Oh, yes. [Laughing] Really weird, I feel the parabola.

Student B: [Laughing] OK, now seriously. You can really feel it.

In this situation, the students held a 3D-printed model of a parabola in their hands. They explained that they could feel the parabola. In general, the qualitative and sensory handling of the models proved an important component of the students' statements. On the basis of this experience, the derivative of a function was described pre-formally and further justifications were given, for example, on the symmetry of the function.

C1.4 Connection of these SDEs The SDEs 'Software Graph Printer' and '3D-printed models', developed during the study, as well as the previous experiences of the students were all initially placed in separate SDEs. Whether these were linked by a superordinate SDE can be examined by the analysis of different situations. The following transcript excerpt, which occurred while working with the software, exemplifies this category: 
Student B: That was $2 x$ to the power of 2 . So, $f$ of $x$ is equal to $2 x$ to the power of

2. OK. [Looks at the laptop] Now we have to get there.

Student C: Enter a function equation. Any.

Student B: [Using the program] There, or what? Yes, exactly.

Student C: We have to do this. [Points to the manual] Then 2 times $x$ times $x$ or so. So, 2 , then this asterisk, $x$, asterisk, $x$.

In the situation described in the transcript, the students create an object using Graph Printer. They have selected the function with the equation $f(x)=2 x^{2}$. The input of the equation into the program is characterised by a special language. Instead of being able to enter a square function directly, it must be written as the product of the identity function. In addition, the product symbol must be converted to an asterisk. With regard to the theory of SDE, the specific language in the software can pose a challenge for the concept formation of the students. However, in the described situation, the students seem to be able to perform the transfer between the computer language and the common mathematical language used in the context of functions. In addition to the specific language, different properties of the objects are focused on in the different SDEs. This becomes clear in the following situation, which takes place when the students worked with the 3D-printed model:

Student C: [Holding the model in his hand] This is some kind of plastic, isn't it? [...] You can really see that this is all still a layer over there.

In this situation, the student described the 3D-printed object. In doing so, he paid particular attention to the material properties, namely the use of plastic and the layered structure of the object. These properties are characteristic for the SDE 3D-printed models. Generally, in this domain of experience, the students discussed a lot about the material conditions of 3D-printed objects (e.g. layered structure, plastic, colour).

However, there were also different situations that indicate the connection of the SDEs to a superordinate one. For example, the students often used the word 'function' in all SDEs. This suggests that in each case they were further developing the concept of function. They also dealt in a reflective manner with the specific properties of the objects in the individual situations. This can be seen in the following example, in which the students described the indicated co-ordinate axis of the 3D-printed model:

Student B: Um, you can't see the axes. Yes, OK, but not all of them.

Student C: Yes, so not like on this.

Student B: Aren't they actually infinitely long?

The students realized that the co-ordinate axes on the model were only indicated. The students knew that co-ordinate axes do not actually have a finite length and that this is only a property of the model. They did not seem to transfer this property to the concept of function.

\section{Category 2: Concept Formation Derivative}

Many elements of the reconstructed SDEs can be attributed to the formation of the concept of derivative. This includes many of the students' statements about feeling the 
slope of the graph with their fingers. These ideas focus on the Grundvorstellungen of covariation and derivative as the tangent slope, and allow further argumentations on this basis. In addition, several global properties of the functions are examined, which is related to the Grundvorstellung of the function as an object.

C2.1 Sensing the Slope of a Graph Several statements of the students concern the sensual experience of the characteristics of curves in relation to the possible actions on function graphs according to Tall (2013). The following excerpt describes the students working with the 3D-printed models:

Student C: The slope is then quasi-like the hand or the complete finger. [Moving the stretched finger over the model]. That's the slope. Do you understand what I mean? [Laughing]

Student B: The slope seems more extreme; don't you think?

Student C: You feel it better. [...]

Student C: I think it's somehow, somehow related to the tangent. The slope of the tangent.

Student B: I don't have the mathematical intuition.

Student C: Yes, we write that the finger is the tangent. [...

Student C: Secant slope. Look at this. When I put my finger on it like this. [Places the finger diagonally over the object]

In this situation, the students re-enacted the actions proposed by Tall (2013). To do this, they moved their outstretched finger in turn over the object. They explained that this enabled them to feel the slope. According to the students, the finger represented the tangent of the graph. The students further explained that by placing the finger diagonally on the model, a secant could be visualized. The empirical work on the models is thus transferred to the empirical theories of the students. They connected certain mathematical concepts (slope, tangent, secant) to actions on the 3D-printed object. Thus, by perceiving the changing slope when moving along the model, they could gain experience with the covariation of a function and learn about essential properties of the tangent of a graph as a derivative. The Grundvorstellungen of covariation and tangent slope seem to be stimulated.

C2.2 Reasoning on the Basis of the Slope In various situations, the students argued based on feeling the slope through the 3D-printed objects. This can be examined in the following situation, in which they described the change of the slope of the polynomial of degree four:

Student B: Because if we say so, then it falls, rises, falls and here it rises again.

[...]

Student C: You can do that so easily with your finger [...] You know? Look, falls, falls, falls, then it rises, then it falls again. [Touches the model]

Student B: What happens to the slope between these two areas? [...] Huh? The slope, there is no slope between the two areas.

Student C: Yes, here! That's zero, then the slope is zero. 
The students described the change of the slope when moving the finger across the model. On this basis, they recognized that the slope is zero at the lowest and highest points. They also explained that the slope is monotonic between the extremal points. Thus, they have developed criteria for the existence and determination of extremal points on a pre-formal level.

Furthermore, the models seemed to draw the students' attention to characteristics of the function as a whole. This can be seen in the following example, where students used the models to investigate symmetries:

Student C: You can do that so easily with the finger. You know? Look, falls, falls, falls, then it rises, then it falls again.

Student B: [Reading] Is the function symmetrical?

Student C: Because the slope here is exactly the same, um, the falling slope here is the same as the rising slope here. [Pointing to the model]

In the described situation, the students operated with the model and argued for the symmetry of the graph of the function on the basis of the action. Empirical arguments are presented to justify the empirical theory of the students. The global property of symmetry can be recognized and justified. This addresses the Grundvorstellung of the function as an object.

\section{Category 3: Objects of Reference}

The students frequently referred in their argumentations to the empirical objects provided throughout the study, which suggests that they had developed an empirical theory of concepts of calculus. The empirical objects were primarily the 3D-printed objects, as well as representations in Graph Printer. In addition, there were several other objects that the students already knew from their mathematics lessons.

C3.1 Object of Reference "Virtual 3D-Models" The students referred in their argumentations several times to the interface of Graph Printer. This can be seen in the following situation:

Student C: Yes, so $z$ is the depth.

Student B: So, it's open downwards? Huh?

Student C: No, because, um, you have to turn it so that $y$ is up here and $[\ldots]$

Student B: Like this? No. [Laughing]

Student C: Something like that. Now, it's just like that from behind. There is no minus in front of it. That's why it's actually open to the top. Otherwise there would be a minus in front of the equation.

In their explanations, the students dealt with and described the virtual 3D-model. The entered functional equation seems to be have been used in particular to determine the shape of the 3D-model. Thus, the virtual 3D-model is an empirical object of reference for the concept of function in the empirical theory of the students. 
C3.2 Object of Reference "3D-Printed Models" The 3D-printed models were used in various situations by the students to develop and investigate hypotheses. This occurred, for example, in the following situation (also described above):

Student B: [Reading] Is the function symmetrical?

Student C: Because the slope here is exactly the same, um, the falling slope here is the same as the rising slope here. [Pointing to the model]

In this situation, the students explored the symmetry of the graph using the 3D-printed model. In their reasoning, they referred to actions on the model. Thus, the 3D-printed models are important objects of reference in the empirical mathematical theory of the students. They are described with this theory and are used to further develop the theory.

C3.3 Other Objects of Reference Various other empirical objects of reference were used by the students for the development of concepts. An example of this is the following situation:

Student B: Well, if we would enter the function into our calculator, then it has a minimum and a maximum. And I know, that it won't be this. [Pointing to the screen] Do you know what I mean?

In their reasoning, the student referred to the image that a graphic calculator would generate. The graphs of the graphic calculator were important objects of reference the students knew from their mathematics class.

\section{Discussion}

The analysis of the data with the chosen theoretical framework provides insights into the concept formation processes of the students during the learning situations of the study. The developed knowledge can be described as located in different SDEs. These seem to be encouraged by the contexts of the different phases of the study, hence working with Graph Printer and the 3D-printed models. Besides the context of the study, the statements of the students refer to situations and knowledge from the previous mathematics lessons in class.

Different specifics of the individual subjective domains of experience could be identified. They differed in particular in parts of the language and in the respective focused properties of the objects. Nevertheless, it can be assumed that a unifying SDE was formed by the students, since they used the word 'function' in all situations and dealt with the specific properties of the objects in the different situations in a reflective manner.

The knowledge developed by the students in the SDEs can be combined with the Grundvorstellungen of covariation, of the function as an object and of the derivative as a tangent slope. The students moved a finger across the 3D-printed model and explained that they could perceive the changing slope in this way. This is in connection with the Grundvorstellungen of covariation and of the derivative as the tangent slope. On this basis, various other relations were developed, including criteria for the existence and determination of extreme points and the symmetry of the graph. This 
description of global properties of the function or its graph relates to the Grundvorstellung of the function as an object.

The descriptions of the students show many references to empirical objects. These are the empirical objects of reference for the empirical mathematical theories of the students. These are, in particular, the virtual 3D-models and the 3D-printed models, but also empirical objects already known from previous mathematics lessons, such as graphs of functions generated by a graphic calculator. The empirical objects of reference constituted the SDEs.

\section{Summary and Outlook}

The present article discusses the contribution of 3D-printing technology and 3D-printed models of graphs of functions for concept formation processes of the concept of derivative. The literature review showed that the use of 3D-printing technology has so far been investigated primarily in geometry teaching. Although there are already a few publications on 3D-printing in the calculus, a systematic investigation of concept formation processes with 3D-printed objects is still pending in this field. Therefore, this process was investigated in this article using the example of 3D-printed models of graphs of function.

The theoretical background, framed by the Grundvorstellungen of the concepts of function and derivative from a normative perspective, and by SDE as a descriptive perspective, is embedded in the concept of empirical theories. This constellation has proven to be an effective instrument for the analysis of concept formation processes with empirical models. SDEs of the students could be described in three categories within the empirical study (previous experiences, Graph Printer, 3D-objects), which are characterized by a specific language usage and by objects of reference with specific properties (e.g. the colour of the object). However, the students used the general term 'function' in all cases, which is why the development of a generalizing and comparative SDE can be assumed and suggests that the experiences gained in the study could be integrated in the students' learning of differential calculus.

The results of the analysis show that there might be a potential of the software and the models to foster the development of the Grundvorstellungen of covariation, of the function as an object and of the derivative as the tangent slope. The students used their fingers to point at the model like a tangent and to feel the slope. Further correlations can be worked out based on these experiences. The software and the models facilitate the qualitative learning of important elements of the differential calculus even at an early stage. Since this is not a comparative study with a control group, positive effects cannot be assigned with certainty to these elements of the setting used. However, the many references of the students to the models and the representations in the software suggest a positive influence.

The decisive objects of reference of the empirical theories of the students are the 3Dprinted objects and the graphic representation in Graph Printer. In addition, there are other objects that the students knew from previous mathematics lessons, e.g. graphs of functions generated with a calculator. The possibilities of the 3D-printing technology for concept formation processes in calculus have been investigated using the example of 3D-printed graphs of function. Different potentials and challenges could be 
identified. Further studies will be conducted to investigate the use of this technology in greater depth.

Acknowledgements Open Access funding provided by Projekt DEAL.

Open Access This article is licensed under a Creative Commons Attribution 4.0 International License, which permits use, sharing, adaptation, distribution and reproduction in any medium or format, as long as you give appropriate credit to the original author(s) and the source, provide a link to the Creative Commons licence, and indicate if changes were made. The images or other third party material in this article are included in the article's Creative Commons licence, unless indicated otherwise in a credit line to the material. If material is not included in the article's Creative Commons licence and your intended use is not permitted by statutory regulation or exceeds the permitted use, you will need to obtain permission directly from the copyright holder. To view a copy of this licence, visit http://creativecommons.org/licenses/by/4.0/.

\section{References}

Arzarello, F., Bartolini Bussi, M., Leung, A., Mariotti, M., \& Stevenson, I. (2012). Experimental approaches to theoretical thinking: Artefacts and proofs. In G. Hanna \& M. de Villiers (Eds.), Proof and proving in mathematics education (pp. 97-143). Dordrecht: Springer.

Bauersfeld, H. (1983). Subjektive Erfahrungsbereiche als Grundlage einer Interaktionstheorie des Mathematiklernens und -lehrens. In H. Bauersfeld, H. Bussmann, G. Krummheuer, J. Lorenz, \& J. Voigt (Eds.), Lernen und Lehren von Mathematik: Analysen zum Unterrichtshandeln II (pp. 1-56). Köln: Aulis.

Burscheid, H., \& Struve, H. (2010). Mathematikdidaktik in Rekonstruktion: Ein Beitrag zu ihrer Grundlegung. Berlin: Franzbecker.

Carlson, M. (1998). A cross-sectional investigation of the development of the function concept. In J. Kaput, A. Schoenfeld, \& E. Dubinsky (Eds.), Research in collegiate mathematics education (pp. 114-162). Washington, DC: Mathematical Association of America.

Dilling, F. (2019). Der Einsatz der 3D-Druck-Technologie im Mathematikunterricht: Theoretische Grundlagen und exemplarische Anwendungen für die Analysis. Wiesbaden: Springer.

Dilling, F., \& Witzke, I. (2018). 3D-printing-technology in mathematics education: examples from the calculus. Vietnam Journal of Education, 2(5), 54-58.

Dresing, T., \& Pehl, T. (2015). Praxisbuch Interview, Transkription\&Analyse: Anleitungen und Regelsysteme für qualitative Forschung. Marburg: Eigenverlag.

Dubinsky, E., \& Harel, G. (Eds.). (1992). The concept of function: Aspects of pedagogy and epistemology. Washington, DC: The MathematicalAssociationofAmerica.

Gibson, I., Rosen, D., \& Stucker, B. (2014). Additive manufacturing technologies: 3D printing, rapid prototyping, and direct digital manufacturing. New York: Springer.

Gopnik, A., \& Meltzoff, A. (1997). Words, thoughts and theories. Cambridge: MIT Press.

Greefrath, G., Oldenburg, R., Siller, H.-S., Ulm, V., \& Weigand, H.-G. (2016). Aspects and "Grundvorstellungen" of the concepts of derivative and integral: Subject-matter-related didactical perspectives of concept formation. Journal fürMathematik-Didaktik, 37(1), 99-129.

Halverscheid, S. \& Labs, O. (2019). Felix Klein's mathematical heritage seen through 3D models. In H.-G. Weigand, W. McCallum, M. Menghini, M. Neubrand\& G. Schubring (Eds), The legacy of Felix Klein (pp. 131-152). Cham: Springer.

Hirst, K. (1972). Derivatives and tangents. Educational Studies in Mathematics, 4(3), 299-305.

Hofmann, J., Thormählen, T., \& Büttner, K. (2018). 3D-Druck zur haptischen Darstellung von Grafiken und Graphen in der Blinden- und Sehbehindertenpädagogik. In R. Daschelt \& G. Weber (Eds.), Mensch und Computer 2018 - Tagungsband (pp. 273-277). Bonn: Gesellschaft für Informatik e.V.

Hußmann, S., Rezat, S., \& Sträßer, R. (2016). Subject-matter didactics in mathematics education. Journal für Mathematik-Didaktik, 37(1), 1-9.

Klein, F. (1927/1978). Vorlesungen über die Entwicklung der Mathematik im 19. Jahrhundert. Berlin: Springer. 
Lave, J., \& Wenger, E. (1991). Situated learning: Legitimate peripheral participation. Cambridge: Cambridge University Press.

Malle, G. (2000). Zwei Aspekte von Funktionen: Zuordnung und Kovariation. MathematikLehren, 103, 8-11.

Mayring, P. (2000). Qualitative content analysis. Forum: Qualitative Social Research, 1(2), (20). (http://nbnresolving.de/urn:nbn:de:0114-fqs0002204). Accessed 4/5/2019.

Mayring, P. (2010). Qualitative Inhaltsanalyse: Grundlagen und Techniken. Basel: Beltz.

$\mathrm{Ng}$, O.-L. (2017). Exploring the use of 3D computer-aided design and 3D printing for STEAM learning in mathematics. Digital Experiences in Mathematics Education, 3(3), 257-263.

Ng, O.-L. \& Sinclair, N. (2018). Drawing in space: Doing mathematics with 3D pens. In L. Ball, P. Drijvers, S. Ladel, H.-S. Siller, M. Tabach\& C. Vale. (Eds), Uses of technology in primary and secondary mathematics education: Tools, topics and trends (pp. 301-313). Cham: Springer.

Ng, O.-L., Sinclair, N., \& Davis, B. (2018). Drawing off the page: How new 3D technologies provide insight into cognitive and pedagogical assumptions about mathematics. The Mathematics Enthusiast, 15(3), 563577.

Panorkou, N., \& Pratt, D. (2016). Using Google SketchUp to develop students' experiences of dimension in geometry. Digital Experiences in Mathematics Education, 2(3), 199-227.

Tall, D. (1985). Understanding the calculus. Mathematics Teaching, 110, 49-53.

Tall, D. (2003). Using technology to support an embodied approach to learning concepts in mathematics. In L. Carvalho \& L. Guimaraes (Eds.), História e tecnologia no ensino da matemática (Vol. 1, pp. 1-28). Rio de Janeiro: Cincia Moderna.

Tall, D. (2013). How humans learn to think mathematically. Cambridge: Cambridge University Press.

Tall, D., \& Vinner, S. (1981). Concept image and concept definition in mathematics with particular reference to limits and continuity. Educational Studies in Mathematics, 12(2), 151-169.

Thompson, P., \& Carlson, M. (2017). Variation, covariation, and functions: Foundational ways of thinking mathematically. In J. Cai (Ed.), Compendium for research in mathematics education (pp. 421-456). Reston, VA: National Council of Teachers of Mathematics.

Tiedemann, K. (2016) "Ich habe mir einfach die Rechenmaschine in meinen Kopf gebaut!" Zur Entwicklung fachsprachlicher Fähigkeiten bei Grundschulkindern. Beiträge zum Mathematikunterricht 2016 (pp. 991994). Münster, Germany: WTM-Verlag.

Vinner, S., \& Dreyfus, T. (1989). Images and definitions for the concept of function. Journal for Research in Mathematics Education, 20(4), 356-366.

Vollrath, H.-J. (1989). FunktionalesDenken. Journal für Mathematik-Didaktik, 10(1), 3-37.

vom Hofe, R. (1995a). Grundvorstellungen mathematischer Inhalte. Heidelberg: Spektrum.

vom Hofe, R. (1995b). Vorschläge zur Öffnung normativer Grundvorstellungskonzepte für deskriptive Arbeitsweisen in der Mathematikdidaktik. In H.-G. Steiner \& H.-J. Vollrath (Eds.), Neue problem- und praxisbezogene Forschungsansätze (pp. 42-49). Köln: Aulis.

vom Hofe, R., \& Blum, W. (2016). Grundvorstellungen als stoffdidaktische Kategorie. Journal für Mathematik-Didaktik, 37(1), 225-254.

Witzke, I. (2014). Zur Problematik der empirisch-gegenständlichen Analysis des Mathematikunterrichtes. Der Mathematikunterricht, 60(2), 19-31.

Witzke, I. \& Hoffart, E. (2018). 3D-Drucker: Eine Idee für den Mathematikunterricht? BeiträgezumMathematikunterricht 2018 (pp. 2015-2018). Münster: WTM-Verlag.

Witzke, I., \& Spies, S. (2016). Domain-specific beliefs of school calculus. Journal für Mathematik-Didaktik, 37(1), 131-161.

Publisher's Note Springer Nature remains neutral with regard to jurisdictional claims in published maps and institutional affiliations. 